Анисимов Александр Владимирович, канд. техн. наук, доцент кафедры «Технология производства и переработки продукиии животноводства», Саратовский государственный аграрный университет имени Н.И. Вавилова. Россия.
410005, г. Саратов, ул. Соколовая, 335.

Тел.: (8452) 69-25-32.

ключевые слова: гидротермическая обработка; сушка; экстремальное планирование эксперимента; параметр оптимизации

\title{
RESULTS OF PILOT STUDIES OF THE CAR FOR GRAIN PROCESSING
}

Anisimov Alexander Vladimirovich, Candidate of Technical Sciences, Associated Professor of the chair "Technology of Production and Processing of Livestock Products", Saratov State Agrarian University named after N.I. Vavilov. Russia.

Keywords: hydroheat treatment; drying; extreme planning of an experiment; optimization parameter.

The random balance method was used to select the most significant factors in degree of their influence on the optimization parameter - final moisture content of the material: initial moisture content of the material, power of IR-radiators, machine productivity, and shaft rotation speed. Plan- ning matrix was realized, statistical analysis of the results was carried out by the software Statistica 10.0. On the basis of experimental studies, a mathematical model of the technological process of wheat processing in a peeling and drying machine was obtained. Determined optimal design and operating parameters of the developed peeling and drying machine: at initial moisture content of the material of $19 \%$ (strongly remoistened grain), optimization parameter (the final moisture content of the material) reaches the minimum values - 15.0-15.5\% (an optimum zone), with the minimum machine productivity $500 \mathrm{~kg} / \mathrm{h}$, shaft rotation speed 1350-1400 rpm and power of IR -radiators $4 \mathrm{~kW}$.

\section{ТЕХНОЛОГИЧЕСКИЕ НАПРАВЛЕНИЯ СНИЖЕНИЯ ЭНЕРГОЕМКОСТИ ПРОЦЕССА ОСНОВНОЙ ОБРАБОТКИ ПОЧВЫ}

\author{
БОЙкОВ Василий Михайлович, Саратовский государственный аграрный университет имени \\ Н.И. Вавилова
}

ВОРОТнИкОВ Игорь Леонидович, Саратовский государственный аграрный университет имени Н.И. Вавилова

СТАРЦЕВ Сергей Викторович, Саратовский государственный аграрный университет имени Н.И. Вавилова

БАШМАКОВ Игорь Андреевич, Саратовский государственный аграрный университет имени Н.И. Вавилова

На основе рациональной формулы академика В.П. Горячкина дано определение величины работы или энергии затрачиваемой на обработку определенной площади поля на заданную глубину. В результате теоретических исследований обработки поля по традиционному методу установлены графические зависимости работы затрачиваемой при сплочной обработке 1 га пашни от глубины обработки почвы. В результате теоретических исследований полосовой обработки почвы установлены графические зависимости работы затрачиваемой при полосовой обработке 1 га пашни от ширины полосы при максимальной глубине. Предложены возможные варианты снижения энергоемкости обработки почвы в каждом из рассмотренных способов обработки почвъ.

Введение. В настоящее время на основную обработку почвы расходуется до 40 \% энергозатрат в полеводстве. При этом от качества обработки почвы значительно зависит урожайность сельскохозяйственных культур $[1,5,6,10]$. Учитывая, что в Российской Федерации ежегодно обрабатывается более 70 млн га пашни [5], можно заключить, что снижение энергоемкости и повышение качества обработки почвы является актуальной проблемой. Если рассматривать процесс основной обработки почвы в технологическом плане, то сущность такого процесса заключается в рыхлении площади поверхности поля на заданную глубину, при этом на обработку поля затрачивается определенное количество энергии.

Методика исследований. На основании большого количества теоретических и экспериментальных исследований, а также феноменологического описания технологического процесса основной обработки почвы академиком В.П. Горячкиным была разработана рациональная формула для определения силы тяги конных и тракторных плугов, которая имеет следующий вид (1) [4]:

$$
R_{\text {пл }}=G f+k a b+\varepsilon a B_{\Pi} v^{2},
$$

где $R_{\text {пл }}$ - тяговое сопротивление почвообрабатывающего орудия, $\mathrm{H} ; \mathrm{G}$ - сила тяжести почвообрабатывающего орудия, $\mathrm{H} ; f$ - коэффициент трения корпуса почвообрабатывающего орудия о почву; $k$ - коэффициент, характеризующий способность почвенного пласта сопротивляться деформации, кH $/ \mathrm{M}^{2} ; a$ - глубина обработки почвы, м; в - ширина захвата почвообрабатывающего орудия, м; $\varepsilon$ - коэффициент, зависящий от формы рабочего органа и свойств поч- 


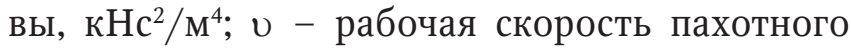
агрегата, м/с.

Формула (1) не рассматривает процесс крошения почвы, но является основой для определения энергоемкости технологического процесса взаимодействия рабочего органа почвообрабатывающего орудия с обрабатываемым пахотным слоем. Она дает только общее представление на что расходуется энергия в процессе обработки почвы и не отражает действительные физические процессы, происходящие при взаимодействии плуга с почвой.

Результаты исследований. Используя рациональную формулу, можно определить величину работы или энергии затрачиваемую на обработку определенной площади поля на заданную глубину. При обработке поля по традиционному методу (рис. 1) величина работы определяется по формуле:

$$
A=\left(G f+\varphi k a_{\text {max }} b+\varepsilon a_{\text {max }} B v^{2}\right) S(B / B),
$$

где $A$ - работа, затрачиваемая на обработку поля на заданную глубину, кДж; $\varphi$ - коэффициент определяющий изменение глубины обработки почвы от максимальной $(\varphi=0-1) ; a_{\max }-$ максимальная глубина обработки почвы, м; $B$ - ширина поля, м; $S$ - длина поля, м; 8 - ширина захвата плуга, м.

Для анализа выражения (2) принимаем размер поля $100 \times 100$ м (1 га), то есть $B=100$ м, $S=100$ м. Обработка поля ведется лемешно-отвальным плугом общего назначения. Сила тяжести плуга 10кН, ширина захвата 2,0 м, при этом согласно [2, 3], $f=0,5 ; k=35,5 \kappa \mathrm{H} / \mathrm{M}^{2} ; \varepsilon=3,43 \kappa \mathrm{Hc}^{2} / \mathrm{M}^{4}$. Максимальная глубина обработки почвы $a_{\max }=0,3 \mathrm{M}, \varphi=1$. Скорость движения $\mathrm{v}=2,5 \mathrm{M} / \mathrm{c}$.

Зависимость работы, выполняемой плугом при обработке 1 га пашни, от глубины обработки почвы представлена на рис. 2.

Анализируя рис. 2, можно заключить, что работа, затрачиваемая плугом на обработку почвы, линейно изменяется от глубины обработки почвы. При глубине обработке почвы $a=0,3$ м она составляет 195800 кДж на 1 га пашни. При глубине обработке почвы $a=0,15 \mathrm{м}$ величина работы в 1,77 раза меньше, чем при глубине 0,3 м. То есть уменьшение глубины обработки почвы традиционным способом позволяет снизить энергозатраты на обработку в 1,77 раза.

В настоящее время в странах ближнего и

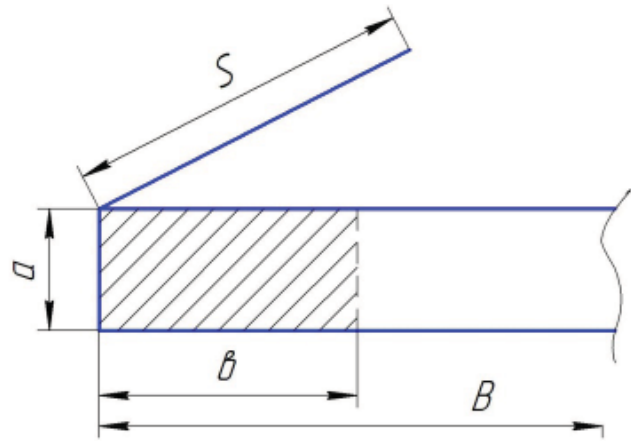

Рис. 1. Схема обработки почвы по первому способу: а-глубина обработки почвы; в - ширина захвата плуга; В - ширина поля; $S$ - длина поля

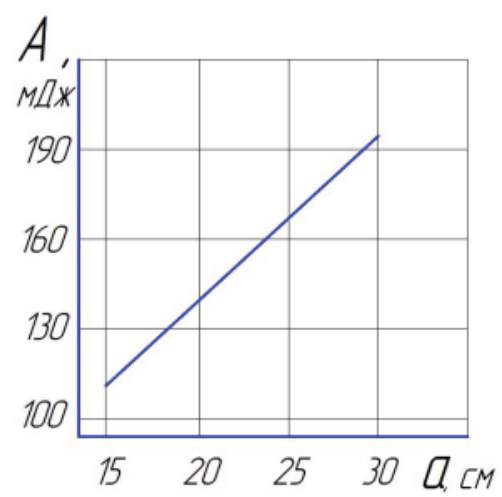

Рис. 2. Зависимость работы А при сплошной обработке одного гектара пашни от глубины обработки почвы а

дальнего зарубежья начинает применяться полосовая обработка почвы $[7,9,11]$, которая выполняется по следующей схеме (рис. 3).

Для анализа энергоемкости обработки почвы по схеме (см. рис. 3) принимаем, что на раму плуга шириной захвата 2,0 м устанавливается четыре рабочих органа, при этом расстояние между рабочими органами составляет 0,67 м. Допускаем, что коэффициенты $f, k$; $\varepsilon$ имеют такую же величину, что и в первом случае. Максимальная глубина обработки $a_{\max }=0,3$ м. Скорость движения $v=2,5 \mathrm{~m} / \mathrm{c}$. Тогда затраты энергии на обработку поля будут определяться по следующей формуле:

$$
\begin{aligned}
A & =\left[G f+\left(\varphi \varphi_{1}+\varphi \varphi_{1} a_{\max } b_{1} k+\right.\right. \\
& \left.\left.+\varepsilon \varphi \varphi_{1} a_{\max } B_{1} v^{2}\right) B / B_{2}\right](B / B) S,
\end{aligned}
$$

где $\varphi_{1}$ - коэффициент, определяющий изменение ширины обрабатываемой полосы $\left(\varphi_{1}=0-1\right)$; в - ширина захвата плуга, м.

На рис. 4 представлена зависимость затраты работы на полосовую обработку почвы при максимальной глубине обработки 0,3 м и различной величине ширины полосы.

Анализ зависимости (см. рис. 4) показывает, что при глубине обработки полосы на 0,3 м изменение затрат работы линейно изменяется от ширины полосы. Если принять ширину полосы 0,20-0,25 м, то затраты энергии относительно обработки пахотного слоя плугом по первому методу (см. рис. 1) на глубину 30 см снижаются

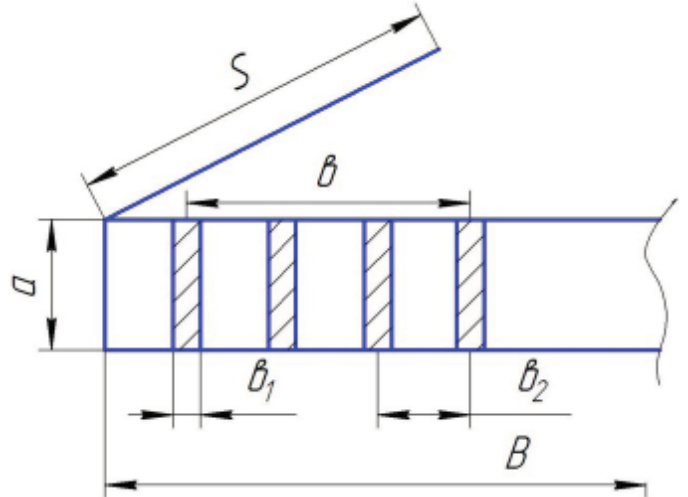

Рис. 3. Схема полосовой обработки почвы по второму способу: $а$ - глубина обработки почвы; в- ширина захвата плуга; В - ширина поля; $S$ - длина поля; $\boldsymbol{B}_{1}$ - ширина полосы: $\boldsymbol{B}_{2}$ - расстояние между полосами: 


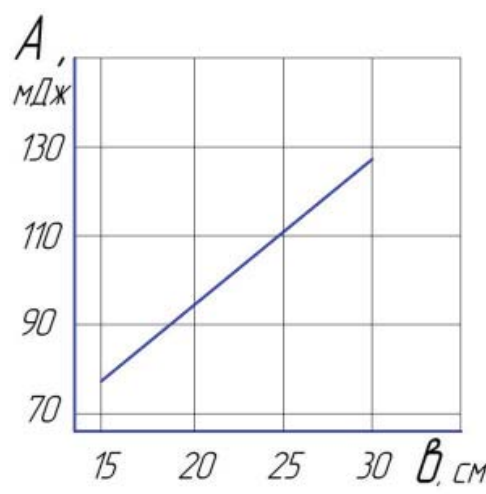

Рис. 4. Зависимость работы А при полосовой обработке 1 га пашни от иирины полосы в при $a_{\text {max }}=0,3 \mathrm{M}$

в $1,77-2,12$ раза.

Также из рис. 2, 4 видно, что при обработке почвы по первому способу на глубину 0,15 м по сравнению с полосовой обработкой с шириной полосы 0,15 м и глубиной 0,3 м энергоемкость уменьшается на $31,1 \%$.

Заключение. В результате проведения теоретических исследований установлено, что возможны два варианта снижения энергоемкости обработки почвы. По первому способу производится сплошная обработка почвы на минимально возможную по агрономическим требованиям глубину обработки. По второму способу обработку следует производить по полосам, размеры которых должны определяться биологическими требованиями, предъявляемыми к росту растений.

\section{СПИСОК ЛИТЕРАТУРЫ}

1. Аристов А.Н., Мулл М.Г. Результаты опытов по определению влияния неравномерности глубины вспашки на потери урожая яровой пшеницы // Почвообрабатывающие и посевные машины и динамика агрегатов: Труды ЧИМЭСХ. - Челябинск, 1972. - Вып. 57. - С. 5-12.

2. Афонин Е.Д., Береславский С.Л. Метод определения коэффициентов рациональной формулы Горячкина В.П. // Механизация и электрификация сельского хозяйства. - 1982 - №4. - С. 42- 44.

3. Вайнруб B.Н. Оптимизация режимов работы пахотного агрегата // Механизация и электрификация сельского хозяйства. - 1980. - № 1. - С. 19-21.

4. Горячкин В. П. Собрание сочинений. Т. 2.М.: Наука, 1970. - 544 с.
5. Князев А.А., Баев Н.К. Исследование влияния неравномерности глубины пахоты на урожайность зерновых культур в условия Среднего Поволжья // Почвообрабатывающие и посевные машины и динамика агрегатов: Труды ЧИМЭСХ, Челябинск, 1972. Вып. 56. - С. 13-18.

6. Лобачевский Я.П. Современные почвообрабатывающие технологии. - М.: МГАУ им. В.П. Горячкина, 1999. - 39 с.

7. Машины, работающие по «полосовому» пути. Технология стрип-тилл. - Режим доступа: https:// propozitsiya.com/mashiny-rabotayushchie-popolosovomu-puti-tehnologiya-strip-till.

8. Несмиян А.Ю. Машинно-технологическое обоснование процессов обработки почвы и посева пропашных культур в условиях дефицита влаги: дис. ... д-ра техн. наук. - Зерноград, 2017. - 424 с.

9. Орлов В.В., Рухлевич Н.B. Strip-till: опыт Самарской области // Ресурсосберегающее земледелие. 2011. - № 3. - C. 18-19.

10. Охинько И.П., Татошин И.Ф. Влияние обработки почвы на дифференциацию обрабатываемого слоя и урожайность зерновых культур // Земледелие. - 1984. № 5. - С. 22- 24 .

11. Сафиулин М. Опыт США: Технология полосовой обработки // Ресурсосберегающее земледелие. 2011. - № 2. - C. 17-19.

Бойков Василий Михайлович, $\partial-p$ техн. наук, проф. кафедры «Процессы и сельскохозяйственные машины в АПК», Саратовский государственный аграрный университет имени Н.И. Вавилова. Россия.

Воротников Игорь Леонидович, $\partial-p$ экон. наук, проф., зав. кафедрой «Проектный менеджмент и внешнеэкономическая деятельность в АПК», Саратовский государственный аграрный университет имени Н.И. Вавилова. Россия.

Старцев Сергей Викторович, $\partial-p$ техн. наук, проф. кафедры «Процессы и сельскохозяйственные машины в АПК», Саратовский государственный аграрный университет имени Н.И. Вавилова. Россия.

Башмаков Игорь Андреевич, аспирант кафедры «Процессы и сельскохозяйственные машины в АПК», Саратовский государственный аграрный университет имени Н.И. Вавилова. Россия.

410056, г. Саратов, ул. Советская, 60.

Тел.: (8452) 73-64-12.

Ключевые слова: обработка почвы; глубина обработки почвы; полосовая обработка почвы; ширина поля.

\section{TECHNOLOGICAL DIRECTIONS OF REDUCING THE ENERGY INTENSITY OF THE PRIMARY TILLAGE PROCESS}

Boykov Vasiliy Mihaylovich, Doctor of Technical Sciences, Professor of the chair "Processes and Agricultural Machinery in AIC", Saratov State Agrarian University named after N.I. Vavilov. Russia.

Vorotnikov Igor Leonidovich, Doctor of Economic Sciences, Professor, Head of the chair "Project Management and Foreign Economic Activity in Agro-industrial Complex", Saratov State Agrarian University named after N.I. Vavilov. Russia.

Startsev Sergey Viktorovich, Doctor of Technical Sciences, Professor of the chair "Processes and Agricultural Machinery in AIC", Saratov State Agrarian University named after N.I. Vavilov. Russia.

Bashmakov Igor Andreevich, Post-graduate Student of the chair "Processes and Agricultural Machinery in AIC", Saratov State Agrarian University named after N.I. Vavilov. Russia.
Keywords: tillage; depth of tillage; strip tillage; field width.

On the basis of the rational formula of academician V.P. Goryachkin, the definition of the amount of work or energy spent on processing a certain area of the field at a given depth is given. As a result of theoretical studies of field processing by the traditional method, the graphic dependences of the work spent in continuous processing of one hectare of arable land on the depth of soil cultivation are established. The theoretical results strip tillage installed the graphics according to the work required in bandpass processing of one hectare of arable land, of the bandwidth at the maximum depth. Possible options for reducing the energy intensity of tillage in each of the considered methods of tillage are proposed. 